\title{
Green Nanochemistry: Metal Oxide Nanoparticles and Porous Thin Films from Bare Metal Powders
}

\author{
Engelbert Redel, Srebri Petrov, Ömer Dag, Jonathon Moir, Chen Huai, \\ Peter Mirtchev, and Geoffrey A. Ozin*
}

Take a metal powder and add aqueous hydrogen peroxide and a small amount of acetic acid (10:1 ratio) under ambient conditions and, in one simple step, colloidally stable dispersions of nanoparticle (NP) metal oxides of the respective metals form with diameters in the range approx. $3-8 \mathrm{~nm}$. No complex work-up or time-consuming purification is required, just simple filtration and spin-coating to make a nanoparticle metal oxide thin film. Furthermore, this straightforward approach avoids expensive organic surfactants, capping ligands and solvents, metal salts, coordination compounds, and sol-gel precursors commonly used in prior reported syntheses of metal oxide nanoparticles that often contaminate and therefore complicate their subsequent utilization. ${ }^{[1,2]}$ This facile synthetic strategy provides a universal, clean, green, and simple approach to metal oxide nanoparticles, as well as single and multilayer metal oxide nanoparticle porous films perceived to provide diverse applications such as lithium batteries, solar and photoelectrochemical cells, electrochromics and sensors, photocatalysts, and photonic crystals. ${ }^{[3-7]}$ Metal oxide nanoparticles and thin films thereof offer distinctive and desirable properties that make them attractive candidates for materials science and biomedical applications. ${ }^{[8]}$

The synthesis begins with micrometer-scale metal powders exemplified by W, Mo, Ni, Co, Fe, Zn, and Mg (purity 99.5 to $99.95 \%$ ) which dissolve in aqueous $/ \mathrm{H}_{2} \mathrm{O}_{2}$ (30 wt \%) and acetic acid, AcH. (DANGER: Very exothermic reaction, instant ice-bath cooling is necessary in a well ventilated fumehood. Protective glasses, gloves, and a lab coat must be worn all the time during this synthetic procedure.) Contingent upon the choice of metal(s), this results in highly stable, single $\left(\mathrm{M}_{1} \mathrm{O}_{\mathrm{x}}\right)$, binary Spinel $\left(\mathrm{M}_{1} \mathrm{M}_{2} \mathrm{O}_{4}\right)$ and ternary multi-metallic $\left(\mathrm{M}_{1} \mathrm{M}_{2} \mathrm{M}_{3} \mathrm{O}_{\mathrm{z}}\right)$ aqueous dispersions of colloidally stable metal oxide nanoparticles (see Figure 1 and Table 1).

Dr. E. Redel, Dr. S. Petrov, J. Moir, C. Huai, P. Mirtchev, Prof. G. A. Ozin Lash Miller Chemistry Department

University of Toronto

Centre for Inorganic and Polymeric Nanomaterials

80 St. George Street

Toronto, M5S 3H6, Ontario, Canada

E-mail: gozin@chem.utoronto.ca

Prof. Ö. Dag

Department of Chemistry

Bilkent University

06800, Ankara, Turkey

DOI: $10.1002 / \mathrm{smll} .201101596$
The synthesis is founded upon a controlled oxidative dissolution process of one or more micrometer-scale metal powder precursors. The role of acetic acid $(\mathrm{AcOH})$ in the dissolution of the metal precursor is envisioned to be manifold: i) it accelerates the metal dissolution process by dissolving passivating metal oxides on the surface of the metal particles $^{[3,7]}$ (acetic acid was shown to etch native metal oxide surfaces): ${ }^{[9]}$ ii) it reacts with $\mathrm{H}_{2} \mathrm{O}_{2}$ to form peroxyacetic acid, ${ }^{[10]}$ which accelerates the oxidative dissolution of the metal nanoparticles; and iii) it enhances the colloidal stability of the metal oxide nanoparticles formed as envisioned in Scheme 1 and Scheme 2.

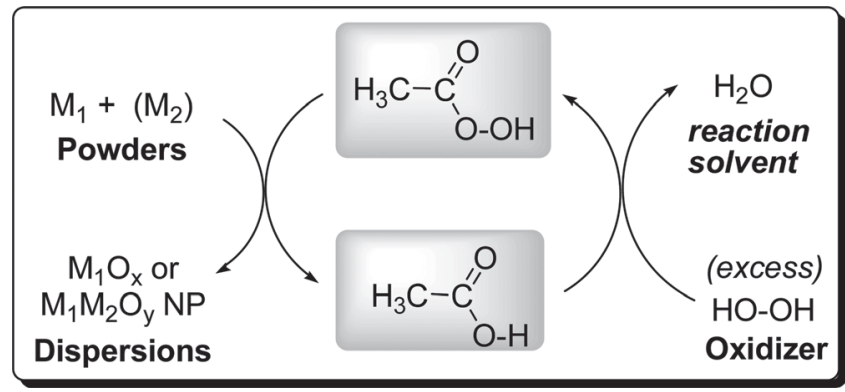

Scheme 1. The role of acetic acid in enhanced oxidative dissolution of micrometer-scale metal particles with $\mathrm{H}_{2} \mathrm{O}_{2}$ to form aqueous dispersions of colloidally stable metal oxide NPs.

The aqueous syntheses described herein are maintained at a low temperature using an ice bath with vigorous stirring until dissolution is complete, achieving essentially total conversion of micrometer-scale metal particles to metal oxide nanoparticles for the metals investigated in this study. In contrast to sol-gel processes, involving, respectively, base- and acid-catalyzed hydrolytic polycondensation reactions of the type $\mathrm{M}-\mathrm{OH} / \mathrm{OR}+\mathrm{HO}-\mathrm{M} \rightarrow \mathrm{M}-\mathrm{O}-\mathrm{M},{ }^{[11]}$ complete etching of the native protective metal oxide shell and any other metal oxide impurities as well as complete oxidative dissolution of the metal precursors occurs to form metal oxide nuclei. Supersaturation ${ }^{[12]}$ of the generated nuclei is then the driving force for nanoparticle growth. Further mechanistic studies are underway in our laboratory to try to define the mode of formation of these metal oxide nanoparticles from bare metal particles and will be presented in another study.

Under acidic conditions ( $\mathrm{pH}$ 1.3-2), the formation of metal acetates is unfavourable due to the high oxidation potential of the $\mathrm{H}_{2} \mathrm{O}_{2} / \mathrm{H}_{2} \mathrm{O}$ redox couple $\left(E_{0}=1.763 \mathrm{~V}\right) .{ }^{[13]}$ Note that 


\section{(a)}

(c)
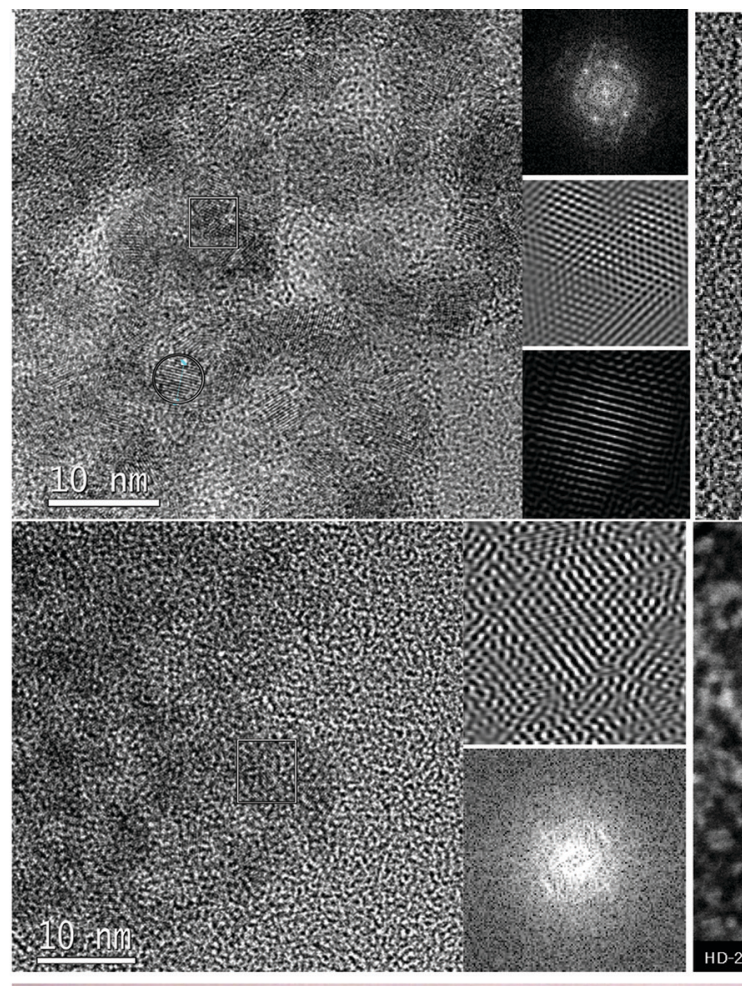

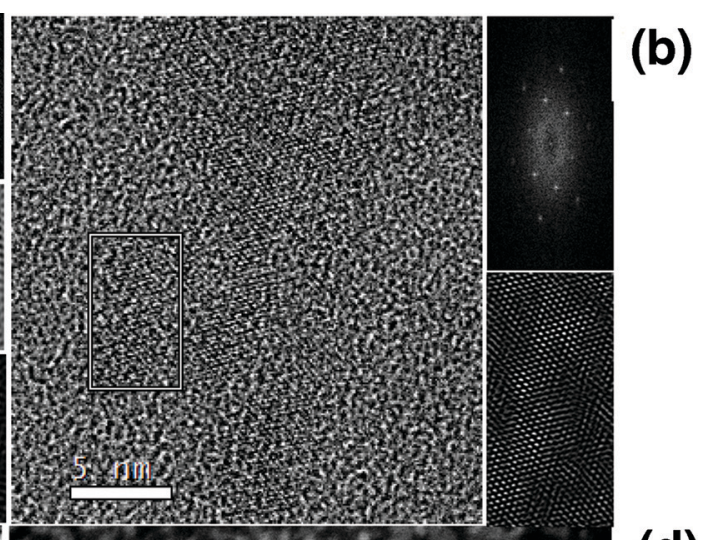

(b)

(d)

(e)

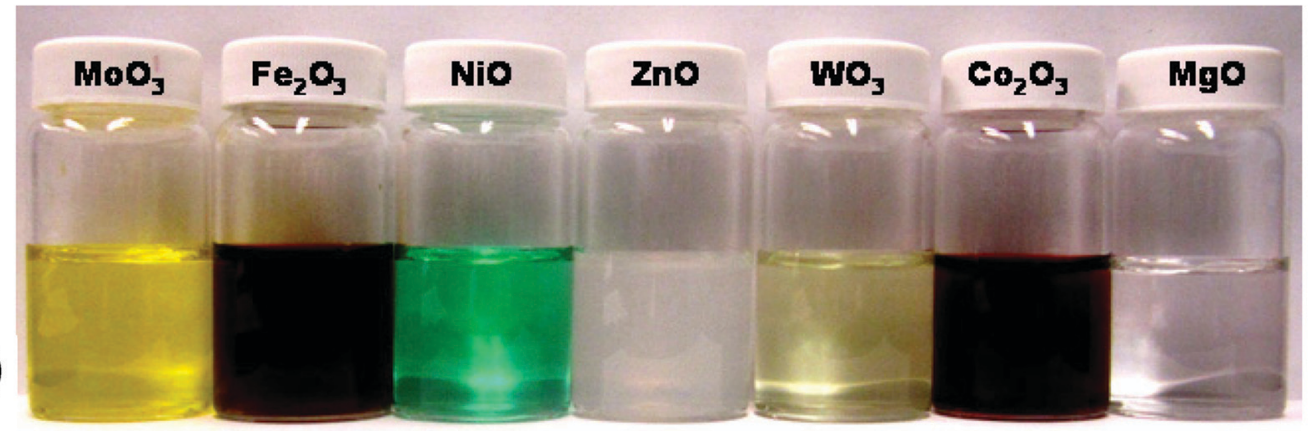

Figure 1. HR-TEM: left columns show the fast Fourier transform (FFT) of a selected square or rectangular region in the images and its inverse FTा of a) $\mathrm{Zn} \rightarrow \mathrm{ZnO}_{2} \mathrm{NPs}$; b) $\mathrm{Fe} \rightarrow \mathrm{Fe}_{2} \mathrm{O}_{3} \mathrm{NPs}$; c) $\mathrm{Mg}+2 \mathrm{Zn} \rightarrow \mathrm{MgZn}_{2} \mathrm{O}_{4} \mathrm{NPs}$, and a STEM image of d) $\mathrm{Ni} \rightarrow \mathrm{NiO}$ NPs. e) Photograph of representative metal oxide nanoparticle aqueous dispersions.

Table 1. Overview of different metal oxide nanoparticle compositions made from metal powders and their particle sizes from STEM, HR-TEM, and PXRD Rietveld refinement.

\begin{tabular}{|c|c|c|c|c|}
\hline Metal precursor & Metal Oxide compositiona) & STEM $[n m]^{b)}$ & Size range $[\mathrm{nm}]^{\mathrm{b})}$ & PXRD size ${ }^{c)}$ \\
\hline Mo & $\mathrm{MoO}_{3}$ & $3.6 \pm 0.5$ & $2.5-4.1$ & $4-5(\mathrm{~S} 1)$ \\
\hline W & $\mathrm{WO}_{3}$ & $3.8 \pm 0.3$ & $2.0-4.7$ & $4-4.5(S 2)$ \\
\hline $\mathrm{Ni}$ & $\mathrm{NiO}$ & $3.1 \pm 0.4$ & $2.2-3.7$ & amorphous \\
\hline Co & $\mathrm{CO}_{3} \mathrm{O}_{4}$ & $6.4 \pm 2.7$ & $4.5-8.3$ & amorphous \\
\hline $\mathrm{Fe}$ & $\mathrm{Fe}_{2} \mathrm{O}_{3}$ & $3.4 \pm 0.5$ & $2.7-4.5$ & $3-3.5(\mathrm{~S} 4)$ \\
\hline $\mathrm{Zn}$ & $\mathrm{ZnO}_{2}(\mathrm{ZnO})$ & $3.9 \pm 0.4$ & $3.1-5.2$ & $3-4.0$ (S5) \\
\hline Mg & $\mathrm{MgO}_{2}(\mathrm{MgO})$ & $4.3 \pm 0.9$ & $3.2-5.7$ & $4.5-5(S 6)$ \\
\hline $\mathrm{Mg}+\mathrm{Co}$ & $\mathrm{MgCO}_{2} \mathrm{O}_{4}$ & $21.4 \pm 5.2$ & $12-27$ & $22 \pm 4$ (S7) \\
\hline$M g+Z n$ & $\mathrm{MgZn}_{2} \mathrm{O}_{4}$ & $3.5 \pm 0.4$ & $2.8-4.6$ & amorphous \\
\hline $\mathrm{Fe}+\mathrm{Co}+\mathrm{Mo}$ & $\mathrm{Fe}_{0.3} \mathrm{Co}_{0.7} \mathrm{MoO}_{4}$ & $3.1 \pm 0.5$ & $2.3-4.3$ & $2.8-3.2(\mathrm{~S} 8)$ \\
\hline
\end{tabular}

a) Stable aqueous acidic dispersion; ${ }^{\text {b) }}$ Average particle-size distributions and size ranges from high-resolution transmission electron microscopy (HR-TEM) and cryo-scanning transmission electron microscopy (STEM) measurements; C)Particle sizes of dried samples from powder X-ray diffraction (PXRD) Rietveld refinement, amorphous samples crystallize after calcination, see Supporting Information. 


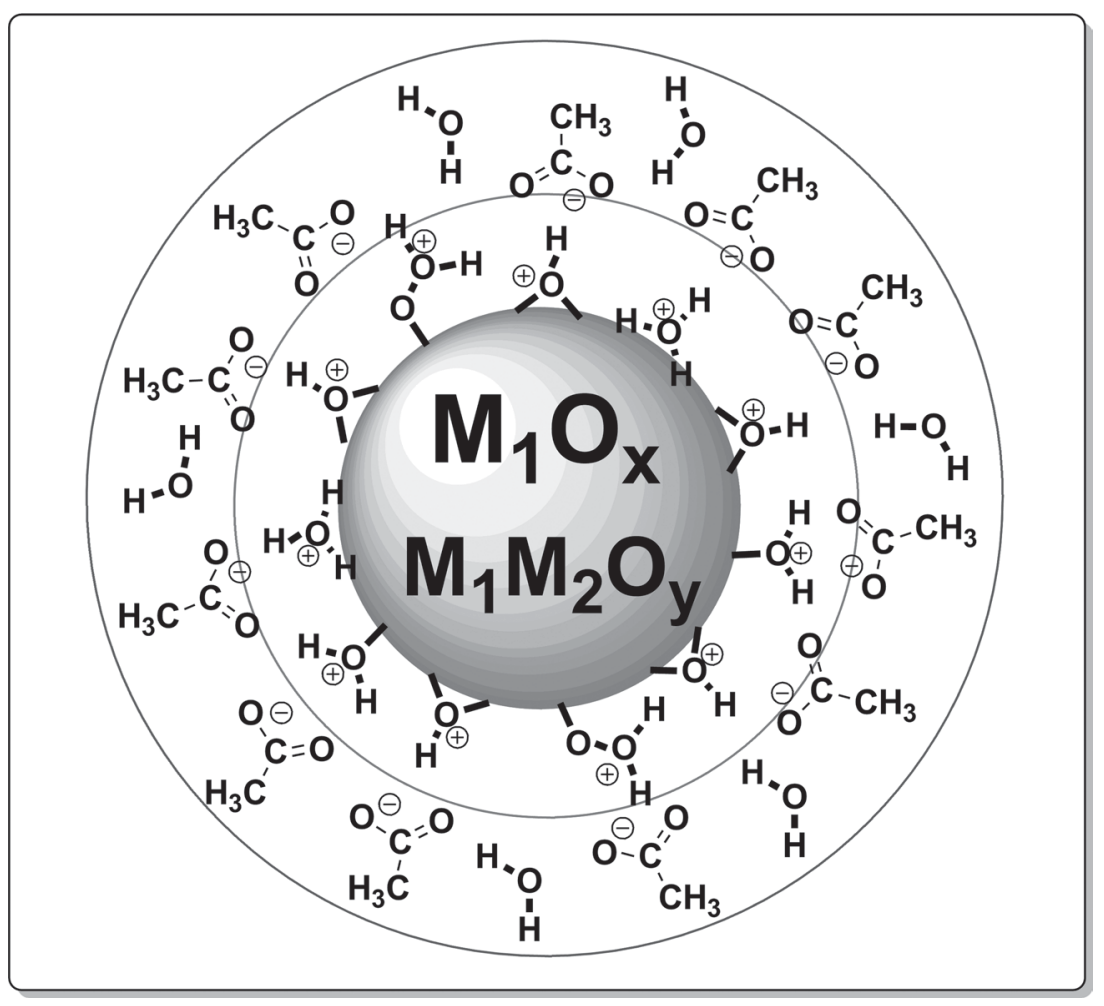

Scheme 2. Illustration of surface charge stabilization, considered responsible for the colloidal stability of metal oxide nanoparticles with a protonated inner Stern Layer and a diffuse counter-anion layer. ${ }^{[23]}$

powder X-ray diffraction (PXRD) of metal acetate reference compounds are shown in the Supporting Information (SI), Figure S19, S20. The oxygen content of the metal oxide nanoparticles so formed is likely provided by the $\mathrm{H}_{2} \mathrm{O}_{2}$ oxidizer, present in excess amounts with small amounts of $\mathrm{AcOH}$ forming a highly reactive peroxoacetic acid intermediate, ${ }^{[10]}$ which is known to transfer one of its oxygens to metal ion species, ${ }^{[14]}$ releasing $\mathrm{AcOH}$ during the synthesis and dissolution process (see Scheme 1). High-purity metal oxide nanoparticle dispersions are obtained under conditions at or below standard laboratory conditions $\left(0-20{ }^{\circ} \mathrm{C}\right)$ by simple stirring and without the need for further washing, extraction, or separation purification steps (for details see Experimental Section). The straightforward nature of this procedure simplifies nanoparticle characterizations and the use of these nanoparticles to form porous single and multilayer thin films with potential utility in gas sensing, ${ }^{[15]}$ catalysis and photocatalysis. ${ }^{[16]}$

Powder X-ray diffraction patterns for synthesized single, binary and ternary metal oxide NPs were measured for powders dried at $80-100{ }^{\circ} \mathrm{C}$ and thin films calcined at $450{ }^{\circ} \mathrm{C}$. PXRD for powder samples provide evidence for the formation of $\mathrm{WO}_{3} \cdot \frac{1}{3}$ $\mathrm{H}_{2} \mathrm{O}$ (hexagonal structure, $\mathrm{P} 6 / \mathrm{mmm}$, isomorphous with $\mathrm{WO}_{3}$ ) and $\mathrm{MoO}_{3} \cdot \frac{1}{3} \mathrm{H}_{2} \mathrm{O}$ (monoclinic structure, $\mathrm{P}_{1} / \mathrm{n}$ ), an amorphous phase for $\mathrm{Ni}$ and $\mathrm{Co}$ oxides, an orthorhombic $\mathrm{Fe}_{2} \mathrm{O}_{3} \cdot \mathrm{H}_{2} \mathrm{O}$ (Goethite structure, $\mathrm{Pbnm}$ ), and a rare cubic structure of magnesium and zinc peroxides: $\mathrm{MgO}_{2}(\mathrm{~Pa}-3)$ and $\mathrm{ZnO}_{2}(\mathrm{~Pa}-3)$. $\mathrm{ZnO}_{2}$ and $\mathrm{MgO}_{2}$ are presumed to be formed from $\mathrm{ZnO}$ and $\mathrm{MgO}$ in an excess of $\mathrm{H}_{2} \mathrm{O}_{2},{ }^{[17]}$ or during the drying/evaporation step. The binary $\mathrm{MgCo}_{2} \mathrm{O}_{4}$ was found to have a Spinel structure
Fd $-3 \mathrm{~m}$, and the ternary multimetal oxide $\mathrm{Fe}_{0.3} \mathrm{Co}_{0.7} \mathrm{MoO}_{4}$ displayed a previously reported monoclinic structure $(\mathrm{C} 2 / \mathrm{m})^{[18]}$ (for details see SI, Figure S1-S8). After spincoating, the metal oxide nanoparticle dispersions and annealing the so-formed films at $450{ }^{\circ} \mathrm{C}$ for $15-20 \mathrm{~min}$, some interesting structural transformations are observed: $\mathrm{ZnO}_{2}$ converts to its common $\mathrm{ZnO}$ Zincite structure $\left(\mathrm{P}_{3} \mathrm{mc}\right), \mathrm{WO}_{3}$ transforms to one of its cubic polymorphs, $\mathrm{NiO}$ crystallizes to cubic NiO Bunsenite, $(\mathrm{Fm}-3 \mathrm{~m})$, the cobalt oxide crystallizes to a $\mathrm{Co}_{3} \mathrm{O}_{4}$ Spinel ( $\mathrm{Fd} 3 \mathrm{~m}$ ), Goethite $\mathrm{Fe}_{2} \mathrm{O}_{3} \cdot \mathrm{H}_{2} \mathrm{O}$ converts to dehydrated $\alpha$ - $\mathrm{Fe}_{2} \mathrm{O}_{3}$ (Hematite, $\mathrm{R}-3 \mathrm{c}$ ), $\mathrm{MoO}_{3} \cdot \frac{1}{3} \mathrm{H}_{2} \mathrm{O}$ converts to its orthorhombic form (Pbnm), and $\mathrm{MgO}_{2}$ converts to rock salt $\mathrm{MgO}$ (Periclase, $\mathrm{Fm}-3 \mathrm{~m}$ ). By contrast, no change in structure is observed for the binary $\mathrm{M}_{1} \mathrm{M}_{2} \mathrm{O}_{4}$ compounds, $\left(\mathrm{MgCo}_{2} \mathrm{O}_{4}\right.$ and $\left.\mathrm{ZnCo}_{2} \mathrm{O}_{4}\right)$ as well as for the monoclinic ternary multi-metal oxide compound $\mathrm{Fe}_{0.3} \mathrm{Co}_{0.7} \mathrm{MoO}_{4}$. For details see the library of PXRD patterns and their analysis in the SI, Figure S9-S18.

Metal oxide nanoparticle sizes of dried dispersions were obtained from the PXRD measurements via full profile Rietveld refinement, ${ }^{[19]}$ and scanning transmission electron microscopy (STEM) and highresolution transmission electron microscopy (HR-TEM) techniques, with good agreement between the applied methods (see Table 1). The HR-TEM and STEM images are provided in Figure 1a-d, demonstrating the spherical morphology and the crystalline pattern of the synthesized metal oxide nanoparticles. The observed lattice fringes, the diffraction spots in the fast Fourier transform (FFT) of the selected area and their inverse FFT show crystalline domains of the corresponding NPs and are all found to be consistent with the PXRD results (see Figure 1). Additional STEM and HR-TEMs images (displaying morphology, size, and shape of the nanoparticles) and details of the TEM analyses for the other compounds are shown in the SI (see Figure S21-S26).

The colloidal stability observed in surfactant-free syntheses most likely originates from the presence of electrical double layer repulsive forces between nanoparticles, ${ }^{[20,21]}$ where surface charges can be traced to ionization of surface groups or adsorption of charged species present in the reaction medium (see Scheme 2). The metal oxide nanoparticles under strongly acidic conditions, $\mathrm{pH} 1.3-2.8$, are likely to be positively charged, ${ }^{[20,21,23]}$ which is consistent with protonated surface oxide and/or hydroxide groups (for zeta potential examples, see SI Figure S37, S38). These stabilizing surfacecapping species include adsorbed hydronium groups $\left(\mathrm{H}_{3} \mathrm{O}^{+}\right)$, protonated hydroxyl groups $\left(-\mathrm{OH}_{2}^{+}\right)$, protonated oxygens $\left(-\mathrm{OH}^{+}-\right)$, as well as protonated peroxo and superoxide groups $\left(-\mathrm{O}-\mathrm{OH}_{2}^{+}\right)$, all envisioned to be present within the inner Stern layer (see Scheme 2). Evidence for the existence of protonated superoxide ${ }^{[22]}\left(\mathrm{O}_{2}^{-}\right)$and peroxide species ${ }^{[22]}$ $\left(\mathrm{O}_{2}{ }^{2-}\right)$ stems from observation of $\mathrm{O}-\mathrm{O}$ vibrational frequencies 
at $1080-970 \mathrm{~cm}^{-1}$ and $820-870 \mathrm{~cm}^{-1}$ in the Raman spectra of representative samples (see SI, Figure S30-S36). The Raman spectra also display diagnostic metal oxide vibrational signatures in good agreement with compositions and phases found by PXRD measurements. The colloidal stability most likely results from the presence of acetate anions $\left(\mathrm{AcO}^{-}\right)$, evidence for which has been found in the Raman spectra of several samples (characteristic peaks at 2940, 1356-1436, and $950 \mathrm{~cm}^{-1}$ traced to $\mathrm{vCH}$, asymmetric and symmetric stretching modes of vCO, and vCC, respectively: see SI, Figure S30-S36).

A library of UV-vis-NIR absorption spectra, scanning electron microscopy (SEM) images and photographs of the metal oxide nanoparticle films, spin-coated and annealed on quartz slides, collectively show the impressive structural integrity, porosity, and optical quality of the films (see SI, Figure S21-S26, S27-S29, S39-S41, S42). The UV-vis-NIR spectra of different metal oxide thin films (shown in SI, Figure S27-S29) display characteristic absorption bands that are slightly blueshifted from their respective bulk metal oxides. The small blueshifts on the bandgaps are attributed to the nanoscale nature of the particles comprising the films as predicted from the PXRD analysis, and the STEM and HR-TEM images (further details of the UV-vis-NIR data can be found in the SI). Note that the particle sizes of commercially available metal oxide nanoparticle dispersions are generally too large $(20-80 \mathrm{~nm})$ to form high-quality optically transparent films. Moreover, most dispersions accessed from other synthetic methods, usually contain extraneous additives, stabilizers, reaction residues, nonaqueous solvents, and so forth that complicate the formation and post-treatment of high-optical-quality nanoparticle porous thin films. In contrast to sol-gel thin film formation, ${ }^{[11]}$ sol-gel methods give either bulk (nonporous) metal oxide films or the crystalline domains are much larger; furthermore, mixed metal oxide, and multi-metallic metal oxide thin films are more difficult or impossible to produce using traditional sol-gel thin-film formation procedures.

Engineering hierarchical multilayer nanoparticle architectures in which the specific properties of the employed metal oxide materials can be usefully exploited provides numerous application opportunities. As an example, Figure 2 shows a crosssectional SEM image of a four-layer film, made up of different metal oxide nanoparticles of $\mathrm{ZnO}, \mathrm{WO}_{3}, \mathrm{Co}_{3} \mathrm{O}_{4}$, and $\mathrm{NiO}$, respectively, prepared by consecutive spin-coating and annealing of each layer at $450^{\circ} \mathrm{C}$ (for more examples, see SI, Figure S39-S41).

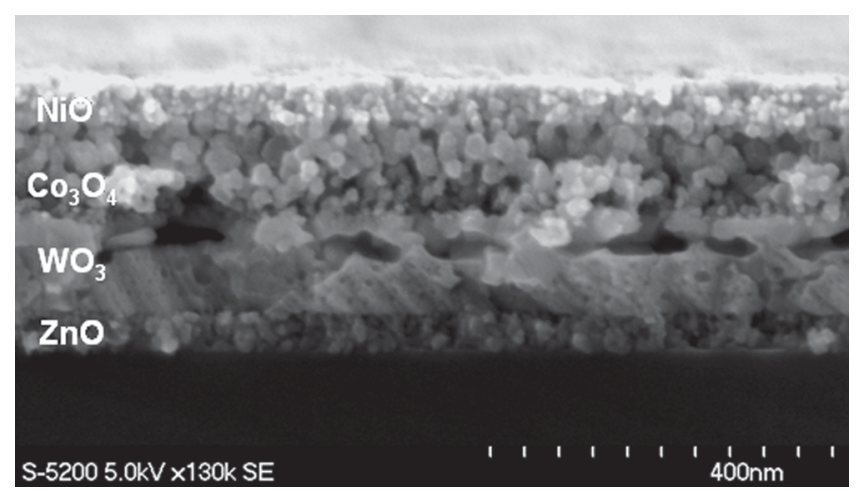

Figure 2. Representative SEM cross section of a spin-coated four-layer nanoparticle $\mathrm{ZnO}, \mathrm{WO}_{3}, \mathrm{CO}_{3} \mathrm{O}_{4}$, and $\mathrm{NiO}$ porous film formed from their respective metal oxide nanoparticle aqueous dispersions.
In conclusion, a universal, simple, robust, widely applicable and cost-effective aqueous process has been presented for the controlled catalytic oxidative dissolution of micrometersized metal powders to form high-purity aqueous dispersions of colloidally stable 3-8 nm metal oxide nanoparticles. Their utilization for making single and multilayer optically transparent, high-surface-area nanoporous films has also been demonstrated. It is anticipated that this facile strategy for synthesizing metal oxide nanoparticles and nanoporous films thereof from bare metal powders will find numerous applications in materials science, engineering, and nanomedicine.

\section{Experimental Section}

SyntheticDetails: Mo, W, Ni, Co, Fe, Zn, Mgmetal powder(ASP1-5 $\mu \mathrm{m}$, mesh 100, 200, and 325, purity 99.9 to $99.9995 \%$ metal basis), $\mathrm{H}_{2} \mathrm{O}_{2}$ (30\% p.a.) were obtained from Alfa Aesar and Caledon Laboratory Chemicals, respectively. Silicon wafers (University Wafer, Lot: 1-800216-8346) were obtained from Wafer World. $\mathrm{WO}_{3}, \mathrm{MoO}_{3}, \mathrm{Fe}_{2} \mathrm{O}_{3}, \mathrm{NiO}$, $\mathrm{ZnO}_{2}(\mathrm{ZnO}), \mathrm{Co}_{3} \mathrm{O}_{4}$, and $\mathrm{MgO}_{2}(\mathrm{MgO}) \mathrm{NPs}$ were synthesized by simple dissolution of $1-3 \mathrm{~g}$ of the elemental metal powder (ASP, mesh 100, 200, and 325), dispersed in 10-15 $\mathrm{mL}$ of deionised $\mathrm{H}_{2} \mathrm{O}\left(0.056 \mu \mathrm{S} \mathrm{cm}^{-1}\right)$ followed by the addition of $10-35 \mathrm{~mL} \mathrm{H}_{2} \mathrm{O}_{2}$ (30\% p.a.) and 1-3 mL of $\mathrm{AcOH}$ (Glacial Acid) (ratio 10:1) at $0^{\circ} \mathrm{C}$ (by cooling the reaction mixture with an ice bath due to an exothermic dissolution/oxidation process) under air, no inert atmosphere (nitrogen) needed, reaction vessels ( 250 or $500 \mathrm{~mL}$ ) should never be closed too tightly. Synthetic procedures for each metal oxide dispersion form respective bare metal precursors were shown to be reproducible at least 3-5 times. (DANGER: Very exothermic reaction, instant ice bath cooling is necessary in a well-ventilated fumehood.) This synthesis procedure should be carried out only under skilled supervision or from a well trained lab-scientist/technician.

The synthesis must be performed in a well ventilated fumehood; addition of $\mathrm{H}_{2} \mathrm{O}_{2}$ (p.a. $30 \%$ ) must be carried slowly, where a permanent cooling is needed during the addition and reaction/dissolution processes. Final stirring of the reaction mixture, at room temperature, overnight or several days leads to a light yellow $\mathrm{WO}_{3}$ dispersion, a yellow $\mathrm{MoO}_{3}$ dispersion, a red-rusty $\mathrm{Fe}_{2} \mathrm{O}_{3}$ dispersion, a green $\mathrm{NiO}$ dispersion, a white-milky $\mathrm{ZnO}$ dispersion, a violetpurple $\mathrm{CO}_{3} \mathrm{O}_{4}$ dispersion and an almost transparent $\mathrm{MgO}$ dispersion. The dispersions were stored in plastic bottles at $4{ }^{\circ} \mathrm{C}$. Binary, spinel, and multi-metallic ternary metal oxide compositions were synthesized by dissolving two or three respective metal powders according to their stoichiometry in the final metal oxides.

The resulting aqueous metal oxide dispersions were filtered through a $0.7 \mu \mathrm{m}$ Titan $2 \mathrm{HPLC}$ Filter Amber (GMF Membrane) and mixed with 2-10 w/w\% polyethyleneglycol (PEG), MW: 20000 before spin-coating on Si-wafers. The addition of PEG was performed to improve nanoparticle adhesion to the substrate and to ensure porosity and good film quality; PEG undergoes complete carbonization upon calcination at $450^{\circ} \mathrm{C}$.

\section{Supporting Information}

Supporting Information is available from the Wiley Online Library or from the author. 


\section{Acknowledgements}

GAO is Government of Canada Research Chair in Materials Chemistry and Nanochemistry. He thanks the Natural Sciences and Engineering Research Council NSERC for strong and sustained support of his research. ER thanks the Alexander von Humboldt $(\mathrm{AvH})$ Foundation for a Feodor Lynen Postdoctoral Fellowship. PM thanks NSERC for a CGSM graduate scholarship. ÖD thanks Bilkent University and the Turkish Academy of Sciences for financial support.

[1] G. R. Patzke, Y. Zhou, R. Kontic, F. Conrad, Angew. Chem. Int. Ed. 2011, 50, 826-859.

[2] M. Niederberger, N. Pinna, Metal Oxide Nanoparticles in Organic Solvents, Springer-Verlag, London 2009, pp. 53-95.

[3] J. A. Rodriguez, M. Fernandez-Garcia, Synthesis, Properties, and Applications of Oxide Nanomaterials, Wiley Interscience, New York 2007, pp. 79-119.

[4] M. Niederberger, M. Antonietti, in Nanomaterials Chemistry: Recent Developments and New Directions (Eds: N. R. C. Rao, A. Mueller, A. K. Cheetham) Wiley-VCH, Weinheim 2007, pp. 119-139.

[5] D. P. Puzzo, L. D. Bonifacio, J. Oreopoulos, C. M. Yip, I. Manners, G. A. Ozin, J. Mater. Chem. 2009, 19, 3500-3506.

[6] J. L. G. Fierro, Metal Oxides Chemistry and Applications, CRC Press, Taylor \& Francis Group, U.S.A. 2006, pp. 413-765.

[7] V. E. Henrich, P. A. Cox, The Surface Science of Metal Oxides, Cambridge University Press, 1994, pp. 77-246.

[8] H. Goesmann, C. Feldmann, Angew. Chem. Int. Ed. 2010, 49, 1362-1395.

[9] a) K. L. Chavez, D. W. Hess, J. Electrochem. Soc. 2001, 148, G640-G643; b) D. A. Hutt, C. Liu, Appl. Surf. Sci. 2005, 252, 400-411.

[10] a) M. B. Smith, J. March, March's Advanced Organic Chemistry $6^{\text {th }}$ Ed., John Wiley \& Sons, Inc. New Jersey, USA. 2007 p. 1773; b) D. Swern, Organic Peroxides, Vol. 1, John Wiley \& Sons, Inc., USA 1970, pp. 313-516.

[11] C. J. Brinker, G. W. Scherer, Sol-Gel Science: The Physics and Chemistry of Sol-Gel Processing, Academic Press, London, UK 1990, pp. 97-228.

[12] a) C. B. Murray, C. R. Kagan, M. G. Bawendi, Annu. Rev. Mater. Sci. 2000, 30, 545-610; b) V. K. LaMer, R. H. Dinegar, J. Am. Chem. Soc. 1950, 72, 4847-4854.

[13] N. Wiberg, Lehrbuch der Anorganischen Chemie, Walter de Gruyter, Berlin 1995, pp. 1843-1846.

[14] P. N. Balasubramanian, T. C. Bruice, Proc. Nat. Acad. Sci. USA 1987, 84, 1734-1738.

[15] L. D. Bonifacio, D. P. Puzzo, S. Breslav, B. M. Willey, A. McGeer, G. A. Ozin, Adv. Mater. 2010, 22, 1351-1354.

[16] U. Heiz, U. Landman, Nanocatalysis, Springer-Verlag, Berlin 2008, pp. 245-374.

[17] M. Sun, W. Hao, C. Wang, T. Wang, Chem. Phys. Lett. 2007, 443, 342-346.

[18] H. Ehrenberg, I Svoboda, M. Wiesmann, H. Weitzel, Acta Crystallograph. C 1999, 55, 1383-1384.

[19] Topas, v.2.1, General Profile and Structure Analysis Software for Powder Diffraction Data User's Manual, Bruker AXS, Karlsruhe, Germany 2003.

[20] E. J. W. Verway, J. Th. G. Overbeek, Theory of the Stability of Lyophobic Colloids, Elsevier, Amsterdam 1948, pp. 22-65.

[21] a) G. Garnweiler, M. Niederberger, J. Mater Chem. 2008, 18, 1171-1182; b) M. Niederberger, G. Garnweiler, Chem. Eur. J. 2006, 12, 7282-7302.

[22] a) K. Nakomoto, Infrared and Raman Spectra of Inorganic and Coordination Compounds, $5^{\text {th }}$ Ed., John Wiley \& Sons, Inc., New York 1997; b) I. E. Wachs, C. A. Roberts, Chem. Soc. Rev. 2010, 39, 5002-5017.

[23] E. Redel, P. Mirtchev, S. Petrov, C. Huai, G. A. Ozin, ACS Nano 2011, 5, 2861-2869.

Received: August 7, 2011

Revised: September 15, 2011

Published online: November 18, 2011 